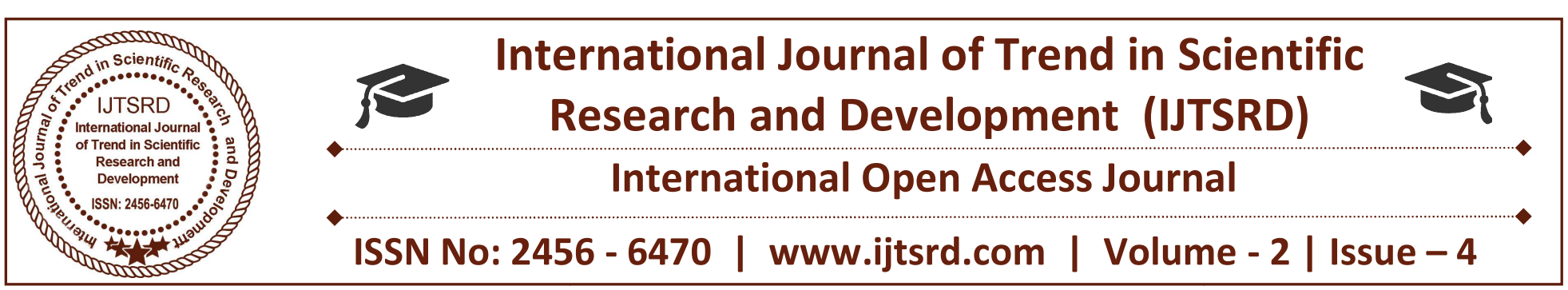

\title{
Study on Comparison of Structural Fundamental Period within UBC -97 and ASCE 7-05
}

\author{
Htun Myint \\ Department of Civil Engineering, Yangon Technological University \\ Yangon, Republic of the Union of Myanmar
}

\begin{abstract}
This study present the comparison of structural fundamental period generated from Equivalent Lateral Force Procedure by applying the provision of two building codes, UBC-97 and ASCE-7-05, to the most common residential buildings of standard occupancy. A sample three story building with two seismic zones (Yangon and Mandalay regions) and different soil types was subjected to code-compliant. All of the design calculations are processed by hand calculation. Furthermore, the comparison of result, such as the response acceleration of each codes will present with design response spectrum curve. For all cases investigated, the UBC was found to be significantly more conservative than ASCE-7-05. Typically, when a jurisdiction develops its own building code, an ASCE 7 edition is frequently adopted. Consequently, the comparisons presented remain relevant even when a local jurisdiction develops its own building code.
\end{abstract}

Keywords: Structural period, Equivalent lateral force procedure, Response acceleration spectra

\section{INTRODUCTION}

In the framework of seismic risk assessment and mitigation, the estimation of fundamental period of buildings is an important issue both for design of new buildings and performance assessment of existing ones. Depending on mass and stiffness, the fundamental period is a global characteristic describing the behavior of building under seismic loads. For this reason, it is easily and directly usable to determinate the global demands on a structure due to a given seismic input. Moreover, the estimation of fundamental period of buildings is useful to identify possible resonance phenomena between buildings and soil vibration. The vibration period of reinforced concrete (RC) buildings is affected by many factors such as structural regularity, number of storeys and bays, dimensions of member sections, infill panel properties and position, load levels, etc. For these reasons, a reliable estimation of the fundamental period of buildings is not easy to carry out and, both in the design of new buildings or in the assessment of existing ones, it is not a priori known (i.e. before analyzing the structural model at hand). To address this issue, several earthquake design codes provide formula in order to estimate the fundamental period of buildings starting from their typological characteristics such as height, framing system and material type. Traditionally the expressions provided worldwide by seismic codes have been obtained by regression analysis of values estimated using both numerical and empirical approaches. All of the calculations presented in this paper are carried out with hand calculations. This comparative study concluded that UBC -97 is more conservative in some cases, however, the results presented are not conclusive enough for structural designers who are evaluating the two codes.

\section{SITE INFORMATIONS}

In this study, the comparison of the structural fundamental period upon a three stories residential building within two building codes ASCE 7-05 and UBC-97 will be subscribed. The proposed building is $30 \mathrm{ft}$ width and $35 \mathrm{ft}$ in length. The typical floor height above the ground is $36 \mathrm{ft}$. The proposed structure is standard residential building and considered that at two seismic zones Yangon and Mandalay regions with variable soil types $\mathrm{A}$ to $\mathrm{E}$. 
The earthquake loads are considered according to ASCE7-05, UBC-97 and MNBC code respectively. The structural members for reinforced concrete are designed according to ACI 318-05.

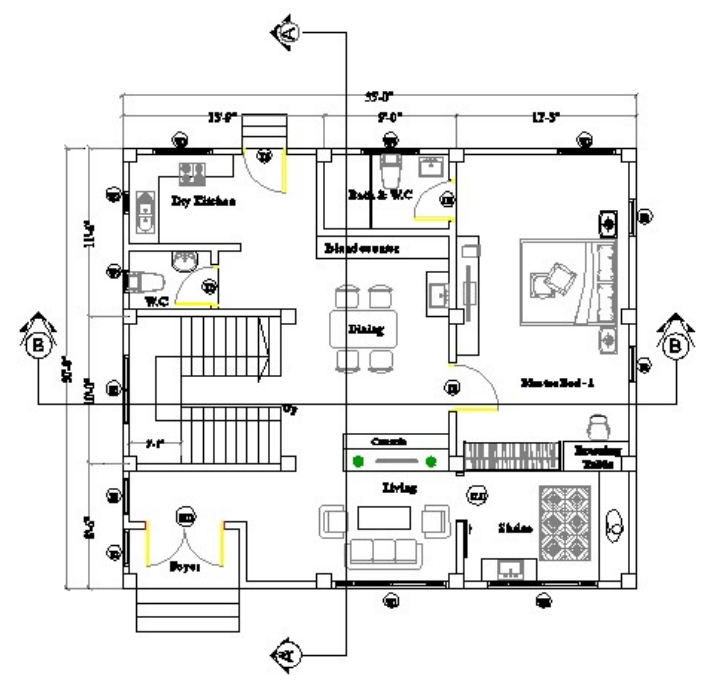

\section{Design spectra cases}

Sample building described in figure 1 to gain insight on the effect of various parameters and to verify the results using hand calculations. It is a3- story reinforced concrete building with all columns of $14 " \mathrm{x} 14$ " and beams of 12"x12" cross-sections. According to the variable soil classes and different seismic zones, there are 10 spectra case for standard building. The following table.1 present the design spectra cases with it's required seismic coefficients.

Fig.1. Proposed 3-storeyed residential building (Typical floor plan)

Table1 Design Spectra Cases

\begin{tabular}{|c|c|c|c|c|c|c|c|c|c|}
\hline \multirow[b]{2}{*}{ Ũ } & \multirow{2}{*}{ 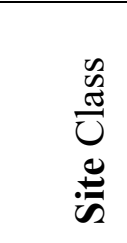 } & \multirow{2}{*}{ 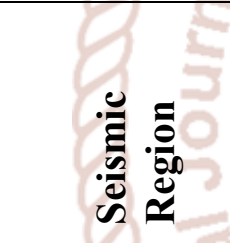 } & \multicolumn{3}{|c|}{ UBC-97 frend in Sc } & \multicolumn{3}{|c|}{\begin{tabular}{|l|l|l|l|}
\multicolumn{2}{|c|}{ ASCE-7-05 } \\
\end{tabular}} & \multirow[b]{2}{*}{$F_{v}$} \\
\hline & & & $\begin{array}{l}\text { Seismic } \\
\text { zone }\end{array}$ & $C_{a}$ est & $C_{v}$ Clic & $S_{S}$ & $S_{1} \quad$ & $F_{a}$ & \\
\hline 1 & A & Yangon & $2 \mathrm{~B}$ & 0.16 & 0.16 & 0.77 & 0.31 & 0.8 & 0.8 \\
\hline 2 & B & Yangon & $2 \mathrm{~B}$ & $0.2 S N:$ & $0.26=6$ & 0.77 ○ & 0.31 & 1 & 1 \\
\hline 3 & $\mathrm{C}$ & Yangon & $2 \mathrm{~B}$ & 0.24 & 0.32 & 0.77 & 0.31 & 1.091 & 1.489 \\
\hline 4 & $\mathrm{D}$ & Yangon & $2 \mathrm{~B}$ & 0.28 & 0.4 & 0.77 & 0.31 & 1.191 & 1.777 \\
\hline 5 & $\mathrm{E}$ & Yangon & $2 \mathrm{~B}$ & 0.34 & 0.64 & 0.77 & 0.31 & 1.173 & 2.754 \\
\hline 6 & A & Mandalay & 4 & 0.3 & 0.32 & 2.01 & 0.8 & 0.8 & 0.8 \\
\hline 7 & B & Mandalay & 4 & 0.4 & 0.4 & 2.01 & 0.8 & 1 & 1 \\
\hline 8 & $\mathrm{C}$ & Mandalay & 4 & 0.4 & 0.56 & 2.01 & 0.8 & 1 & 1.3 \\
\hline 9 & D & Mandalay & 4 & 0.44 & 0.64 & 2.01 & 0.8 & 1 & 1.5 \\
\hline 10 & $\mathrm{E}$ & Mandalay & 4 & 0.36 & 0.96 & 2.01 & 0.8 & 0.9 & 2.42 .4 \\
\hline
\end{tabular}




\section{COMPARISON OF STRUCTURAL PERIOD}

Table1 Comparison of structural period

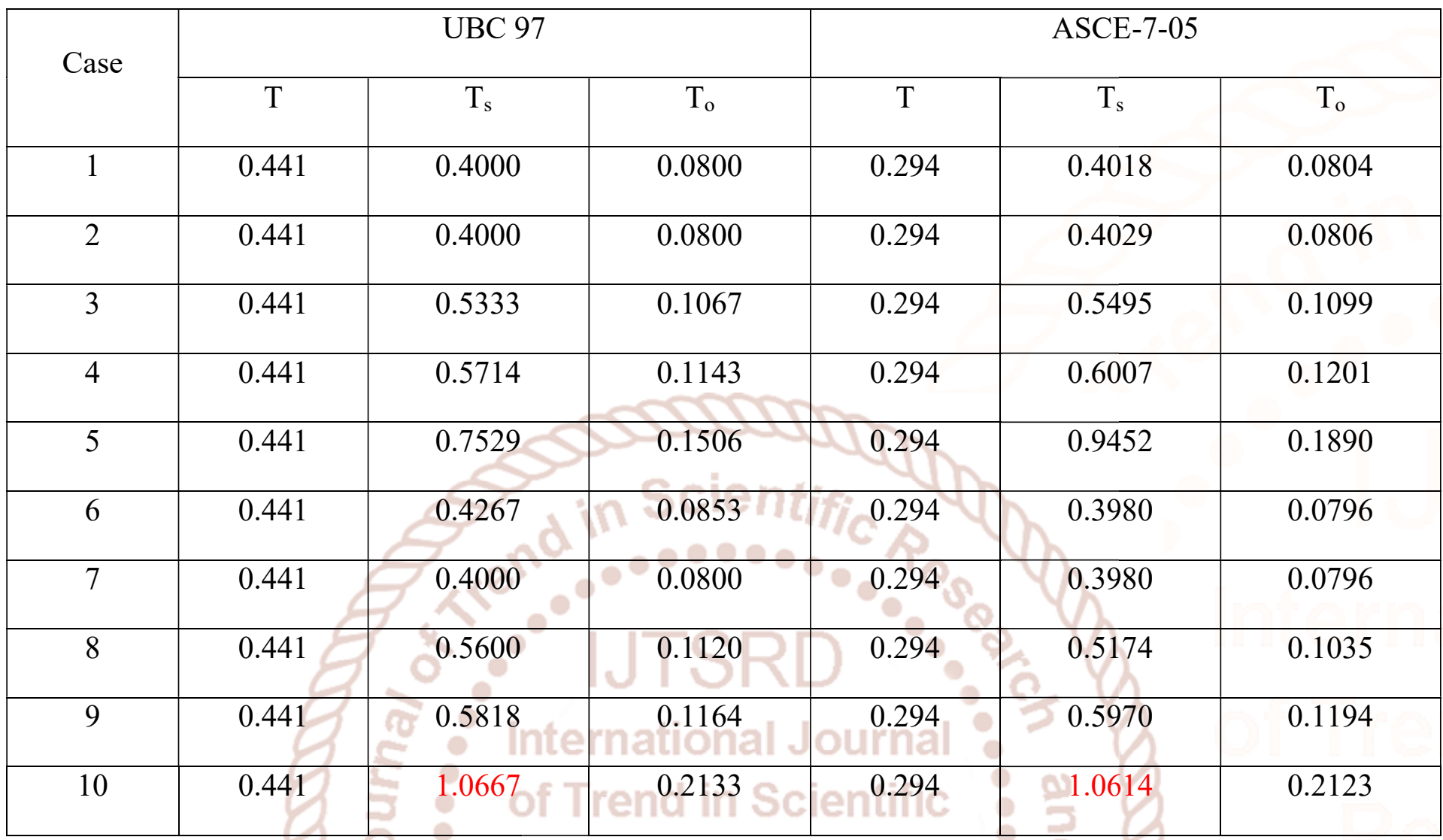

According to variable soil profiles and different seismic zones, using the formulation of fundamental period ( $\mathrm{T}$ ) with two codes UBC -97 and ASCE 7-05, the study is resulted into 10 cases. Each cases have different soil type and variable seismic zone that result the different initial and short period $\left(T_{s}\right.$ and $\left.T_{o}\right)$ also with different spectral acceleration even though they have same story height, material properties and structural fundamental period. The most significant result occurs at Case 10 with soil type E and seismic zone 4 . The value of short period is greater than 1 second in both codes.

\section{COMPARISON OF RESPONSE SPECTRA CASES}

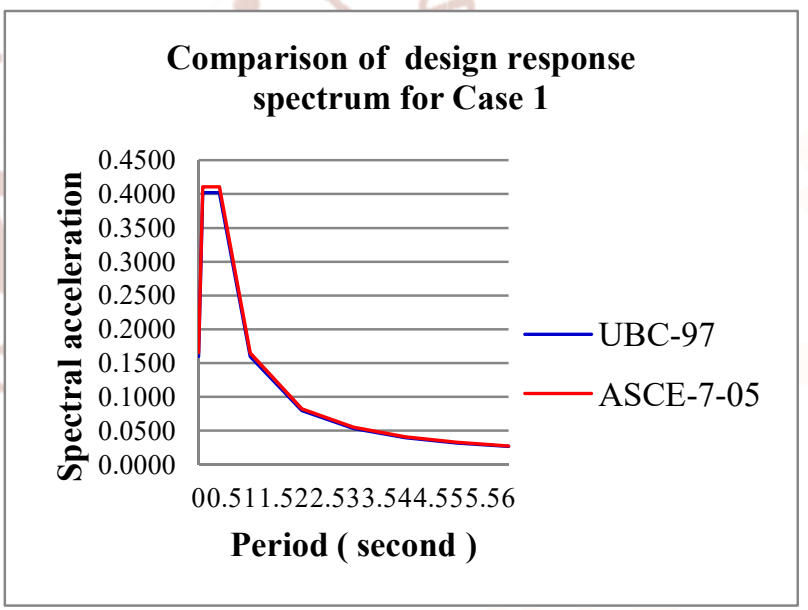

In this result, the initial period is $0.0804 \mathrm{~s}$ and short period is $0.4018 \mathrm{~s}$. According to the above table, for soil type A with seismic zone $2 \mathrm{~B}$, the result of the result of the spectral acceleration is not differ too much for both codes. 
International Journal of Trend in Scientific Research and Development (IJTSRD) ISSN: 2456-6470

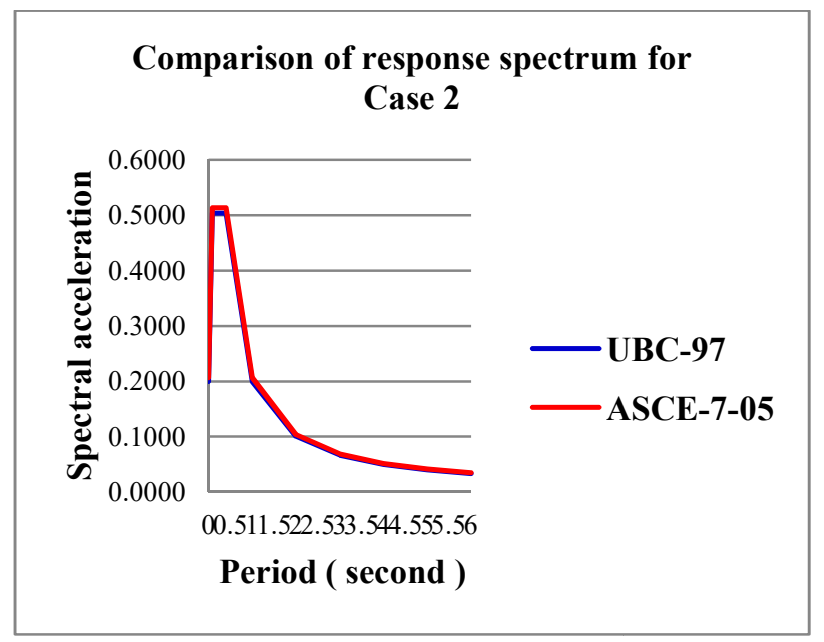

In this result, the initial period is $0.0806 \mathrm{~s}$ and short period is $0.4029 \mathrm{~s}$. The result show that for soil type B of seismic zone 2B ( Yangon ), the response of both codes difference is not to much.

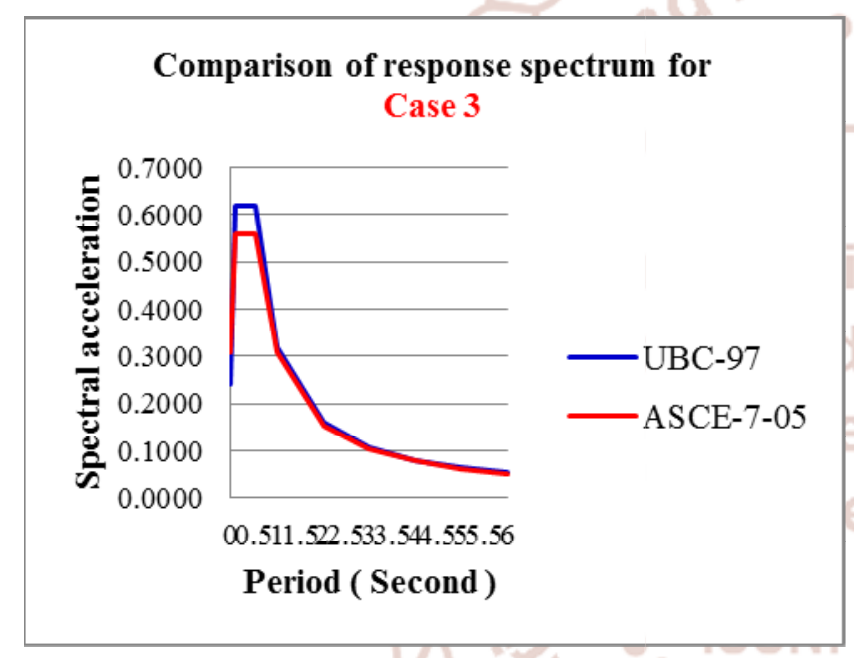

In this result, the initial period is $0.1099 \mathrm{~s}$ and short period is $0.5495 \mathrm{~s}$. The response acceleration value of Case 3 with soil type $\mathrm{C}$ at seismic zone 2B (Yangon ) describe that the response of $\mathrm{UBC}-97$ is greater than ASCE 7- 05 at initial period and short period $\left(T_{o}, T_{s}\right)$

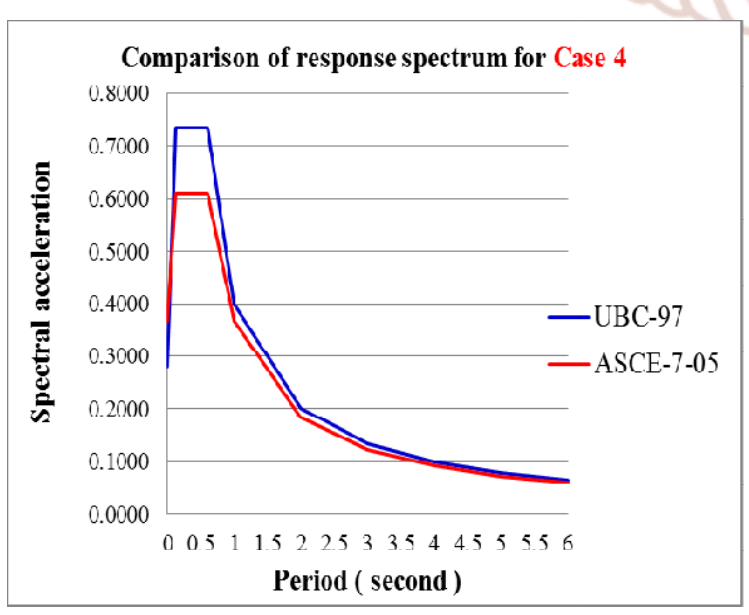

In this case, the initial period is $0.1201 \mathrm{~s}$ and short period is $0.6007 \mathrm{~s}$. When the study is soil type D and seismic zone $2 \mathrm{~B}$, the response acceleration difference between UBC - 97 and ASCE 7-05 is more significant.

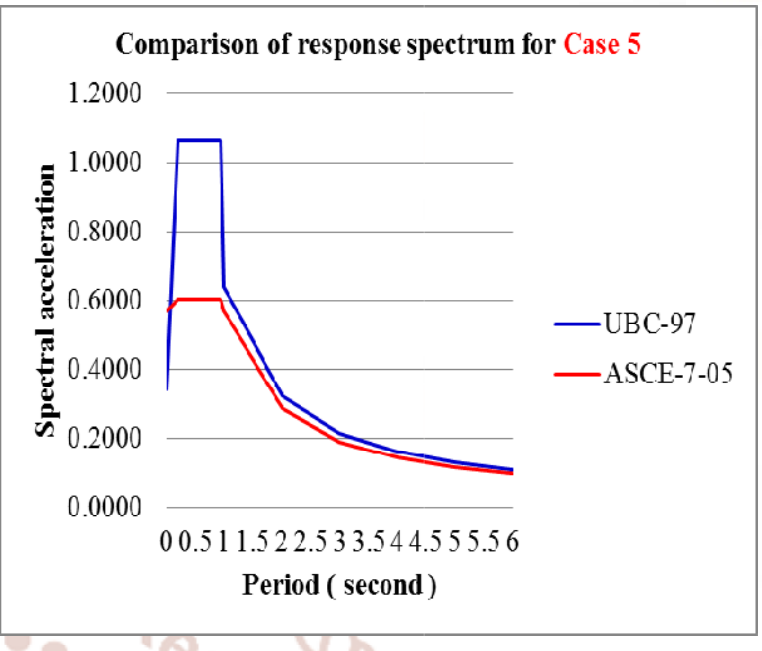

In this study, the initial period is $0.189 \mathrm{~s}$ and short period is $0.9452 \mathrm{~s}$. The result of Case 5 show that when the soil profile become type $\mathrm{E}$ and seismic zone $2 \mathrm{~B}$, the peak response acceleration within initial and short period of UBC -97 is twice the response of ASCE 7-05.

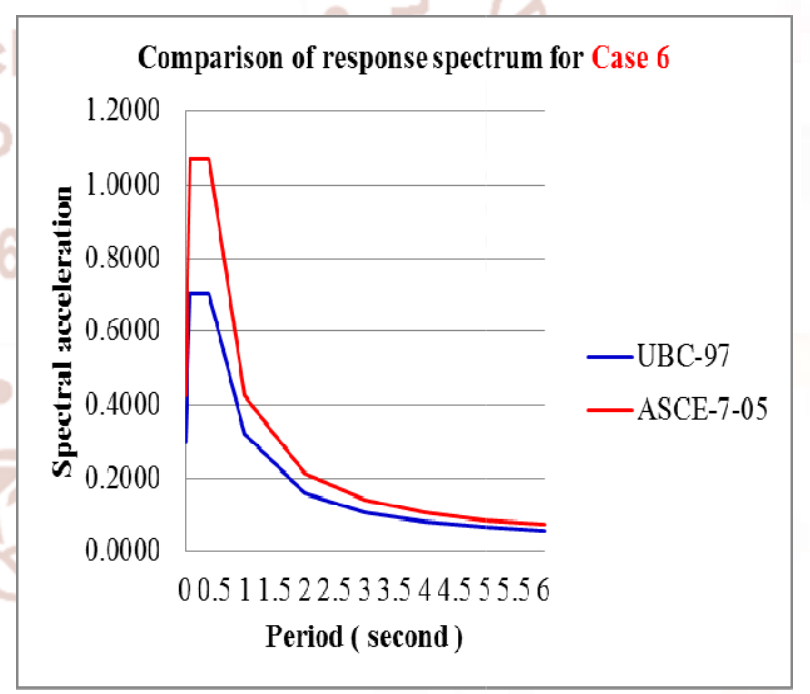

In this case, the initial period is $0.0796 \mathrm{~s}$ and short period is $0.398 \mathrm{~s}$. According to the table, in this study show that when the seismic zone becomes zone 4 (Mandalay), even in the soil type A, the peak response acceleration of ASCE 7-05 is twice in response than $\mathrm{UBC}-97$ within initial and short period. 


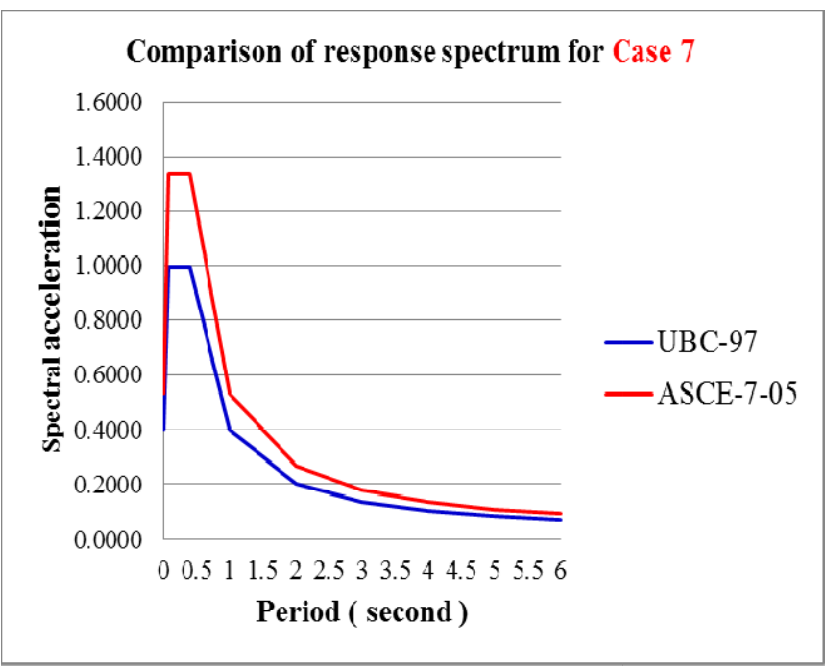

In this result, the initial period is $0.0796 \mathrm{~s}$ and short period is $0.398 \mathrm{~s}$. The result of this table show that the peak acceleration response within initial and short period for ASCE 7-05 is approximately double than UBC -97 at soil type B and seismic zone 4.

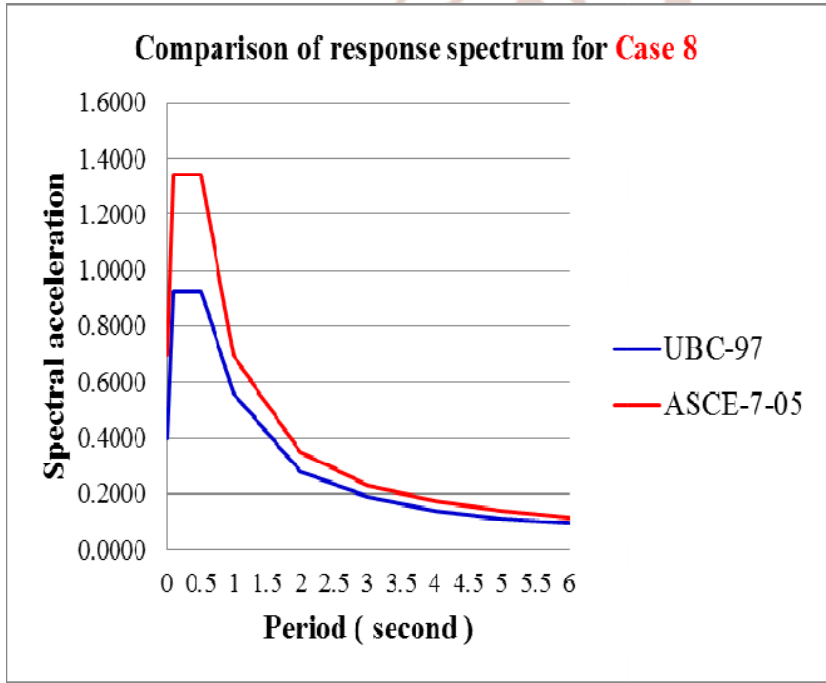

In this result, the initial period is $0.1035 \mathrm{~s}$ and short period is $0.5174 \mathrm{~s}$. This study result shows that the peak response acceleration within initial and short period is approximately the same as the result of case 7. For ASCE 7-05 the peak acceleration remains the same as Case 7 when UBC - 97 response is decreased.

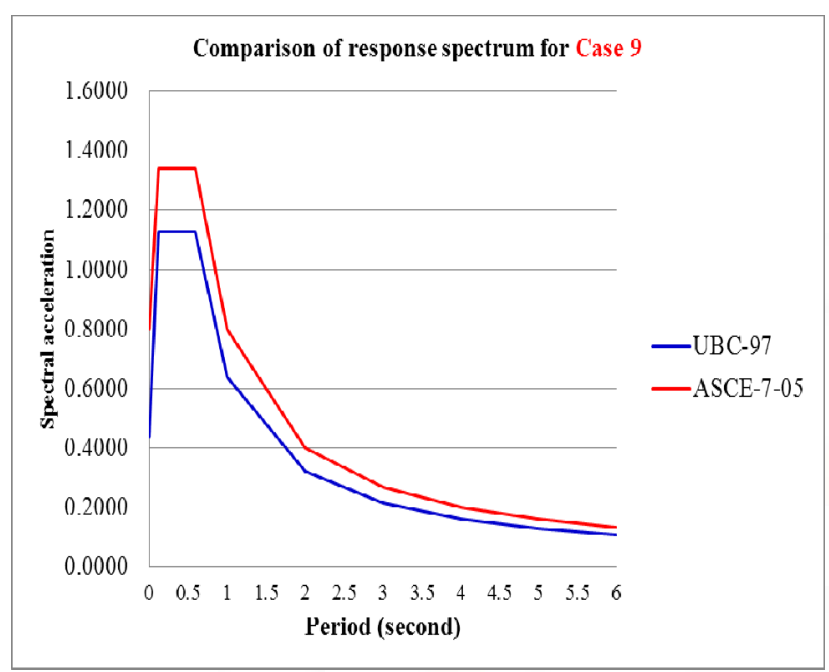

In this result, the initial period is $0.1194 \mathrm{~s}$ and short period is 0.597 . According to the table, when the soil become softer as soil type $\mathrm{D}$, the peak response within initial and short period is not too much differ for both ASCE 7- 05 and UBC -97 at the same seismic zone 4.

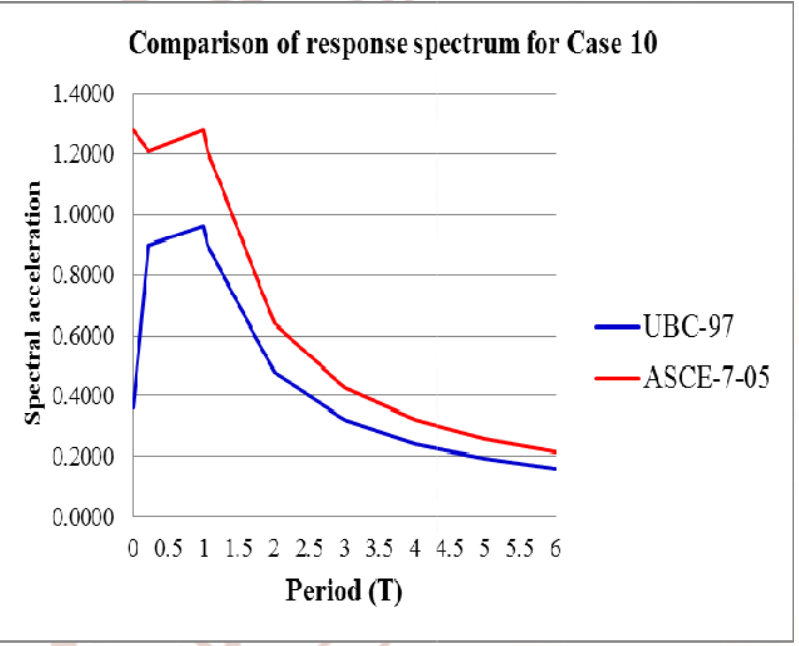

According to the calculation, in Case 10 the initial period is $0.2123 \mathrm{~s}$ and the short period is 1.0614 that is greater than $1 \mathrm{~s}$. This condition is occurred because the soil type is $\mathrm{E}$ and even the seismic zone is at the most severe region. Here, for ASCE 7- 05, the response is higher from the start and then decrease at the initial period and later the response increase again at short period that is greater than $1 \mathrm{~s}$. The peak response acceleration of ASCE 7-05 is greater than UBC - 97 and their response acceleration spectrum.

To accentuate the comparison of ASCE 7-05 and UBC -97, calculating the periods of a regular residential of 12 story building with soil type $\mathrm{D}$ at both seismic zone 2B ( Yangon ) and zone 4 ( Mandalay ).The comparison of period and it's response acceleration and response acceleration spectrum are described as under. 
International Journal of Trend in Scientific Research and Development (IJTSRD) ISSN: 2456-6470

Comparison structural periods between 3 and 12 story building @ Yangon Region for soil type D

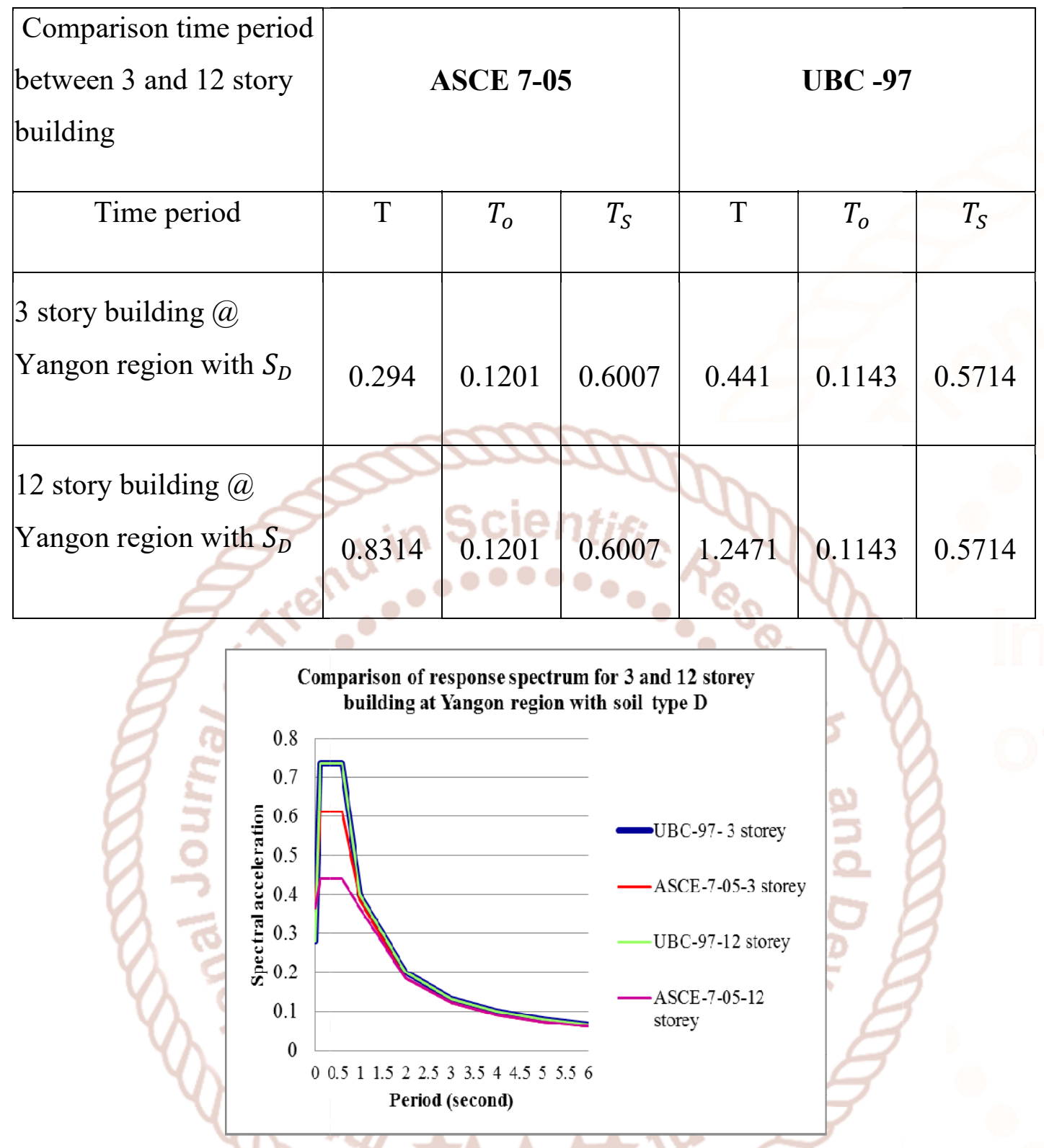

Within initial and short periods, for both 3 story an 12 story, the peak response acceleration of UBC-97 is higher than ASCE 7-05. Comparison structural periods between 3 and 12 story building@ Mandalay Region for soil type D

\begin{tabular}{|c|c|c|c|c|c|c|}
\hline $\begin{array}{l}\text { Comparison time period between } \\
3 \text { and 12 story building }\end{array}$ & \multicolumn{3}{|c|}{ ASCE 7-05 } & \multicolumn{3}{c|}{ UBC -97 } \\
\hline \multicolumn{1}{|c|}{ Time period } & $\mathrm{T}$ & $T_{O}$ & $T_{S}$ & $\mathrm{~T}$ & $T_{O}$ & $T_{S}$ \\
\hline $\begin{array}{l}3 \text { story building @ Mandalay } \\
\text { region with } S_{D}\end{array}$ & 0.294 & 0.1194 & 0.5970 & 0.441 & 0.1164 & 0.5818 \\
\hline $\begin{array}{l}12 \text { storey building @ Mandalay } \\
\text { region with } S_{D}\end{array}$ & 0.8314 & 0.1194 & 0.5970 & 1.2471 & 0.1164 & 0.5818 \\
\hline
\end{tabular}




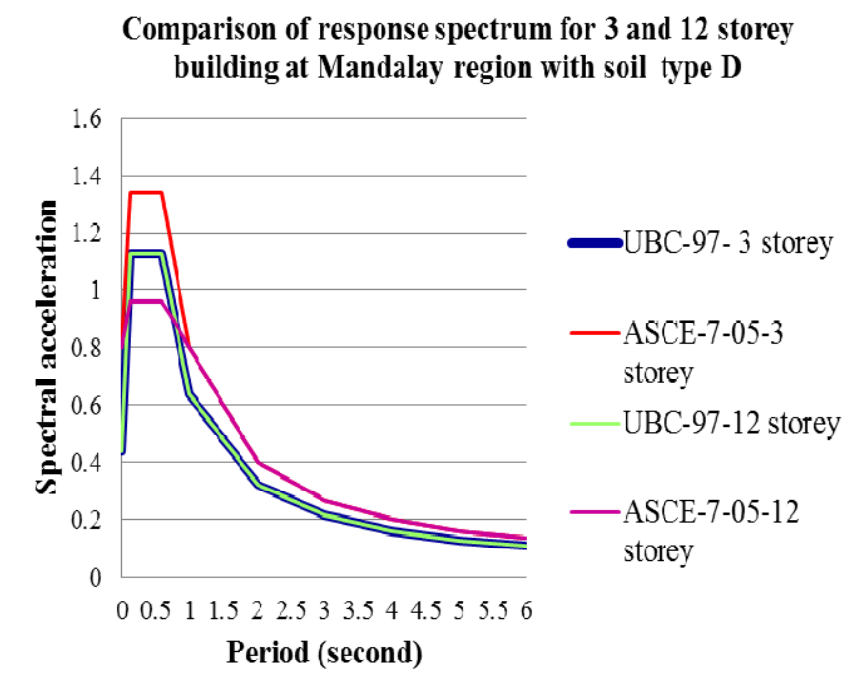

When the seismic zone is 4 (Mandalay region), the peak response acceleration of UBC - 97 for both 3 story and 12 story is the same. Therefore, the effect of story height is not too much influence upon the response acceleration of UBC - 97 when they have same soil type and seismic zone. But for ASCE 7- 05, the peak response acceleration of the structure can vary according to their heights.

\section{DISCUSSION AND CONCLUSION}

A comparison of ASCE 7-05 with UBC -97 has been presented in this study on the specific provision of the two codes for structural fundamental period and it's response acceleration of residential building in the standard occupancy category. The rules are needed by structural engineers and code development authorities in developing country like Myanmar that have a large number of existing buildings designed according to the UBC -97 and need to evaluate their seismic safety. To make valid comparisons in periods, five soil profile in two seismic activity region Yangon and Mandalay have been arbitrarily selected. The design response spectra for all five site classes at two seismic regions were generated with both ASCE 7-05 and UBC - 97 . Here all calculation are hand calculation and the results show that UBC- 97 is suitable for lowrise building with different soil types and seismic region but it is a little conservative than ASCE -7-05. Thereof, ASCE 7-05 has the different response spectra according to their in variable soil class and seismic region. So, ASCE -7- 05 has greater results for high- rise buildings. In ASCE 7, it has been emphasized that ASCE is more preferable for building greater than $65 \mathrm{ft}$. So the designer can use ASCE 7 for both low-rise and high-rise buildings but the section properties will be much larger and will not economic for using in low-rise buildings with ASCE 7. Therefore, this study present the outstanding of an important earthquake engineering research issue concerning ASCE and the UBC. The results presented herein will help structural designers as well as the development of Myanmar National Building Code (MNBC).

\section{REFERENCE}

[1] ASCE/SEI 7-05, Minimum Design Loads for Buildings and other Structures - Theory and Applications to Earthquake Engineering, $3^{\text {rd }}$ ed., Pear Prentice Hall, New Jersey,2007.

[2] Myanmar National Building Code 2016. (MNBC).

[3] Uniform Building Code (UBC-97). Volume 2. U.S.A: "Structural Engineering Design Provision" International Conference of Building Officials. 1997. 